\title{
THE DEVELOPMENT OF METAL OVERLAYERS WITH SMOOTH AND ROUGH TOPOGRAPHIES
}

\author{
A. J. Arvia,* R. C. Salvarezza and W. E. Triaca \\ Instituto de Investigaciones Fisicoquímicas Teóricas y Aplicadas (INIFTA), Facultad de Ciencias Exactas, \\ Universidad Nacional de La Plata, Sucursal 4, Casilla de Correo 16, 1900 La Plata, Argentina
}

(Received 9 January 1989)

\begin{abstract}
A review of the recent advances made in the development of metal electrode surfaces with preferred crystallographic orientations and different roughnesses through the application of periodic potential treatments is presented. The different techniques are described for fec metals in aqueous solutions with particular attention to platinum and gold. The probable mechanisms of the different electrochemical processes which are responsible for the changes in the surface structure of those metals are discussed. The possibility of modelling the growth of metal surface morphologies are considered as well as the importance of scanning tunneling microscopy imaging to assurc the validity of proposed models.
\end{abstract}

\section{INTRODUCTION}

In recent years the advances of surface science have been extremely important to provide a better knowledge of many basic aspects of heterogeneous catalysis, including electrocatalysis, in terms of catalyst structure at the atomic level. Those advances are very useful to attempt to fill the experimental gaps existing between surface science, heterogeneous catalysis, and electrocatalysis $[1-5]$, such as those related principally to the degree of dispersion of the active solid phases and the distribution of crystallographic planes at the surface. Thus, in solid-gas interface experiments usually a very low dispersion of the active material is employed, such as films made of single crystal planes in contact with a gas phase at a low pressure $\left(10^{-11}-10^{-13}\right.$ torr $)$. Conversely, in solid-gas interface catalysis a very high dispersion of polycrystalline solid catalysts is generally involved, sometimes reaching dispersions at the atomic scale, and the gas pressure is in this case relatively high $\left(10^{5}-10^{7} \mathrm{~Pa}\right)$. On the other hand, in electrocatalysis, such as in the case of a solid electrode in contact with an electrolyte solution under gas saturation, the operation conditions cover ranges which can be even wider than those generally found in heterogeneous catalysis. The electrode material (electrocatalyst) can be employed at low, intermediate or very high degree of dispersion and the crystallographic plane distribution at the surface can be varied from that corresponding to single crystal surfaces to those of polycrystalline conducting or semiconducting materials or liquid metals, without definition of crystal planes. The knowledge of these aspects is required to manipulate in a rational way two important characteristics of the solid catalyst (electrocatalyst), namely, the energy distribution of reacting sites, ie the nature of the active site, and the surface roughness, ie a parameter which can be related to the number of

* This paper is based on the plenary lecture delivered by Prof. A. J. Arvia at the Fischer Symposium, Karlsruhe, Germany (1988). active sites available for the reaction per unit area. These two characteristics become essential for defining the efficiency of metal electrocatalysts [6-8]. The deeper and wider understanding of these problems should be encouraged in order to develop an electrocatalyst engineering approach.

The concept of roughness which is frequently used both in heterogeneous catalysis and electrocatalysis is related to the size and morphology of dispersed material particles and capillary effects appearing through porosity. The roughness as well as the so-called roughness factor definitions are directly concerned with the methods of evaluation of the real surface area of electrocatalysts $[9,10]$. In addition the behaviour of an electrocatalyst for a particular reaction depends on the surface accessibility to reactants, geometry related to the distribution of reacting centers, and diffusion resistance for reactants and products.

The recent development of scanning tunneling microscopy (STM) offers for the first time the fossibility to inspect the surface topography of solid materials at the nanometer scale[11-13]. Through STM it becomes possible to establish unambiguously for electrodispersed metal overlayers such as those of $\mathbf{P t}$ and $\mathrm{Au}[14,15]$ the extent of surface homogeneity, the morphology of the rough surface, the particle size distribution, the shape of dispersed particles, the presence of a particular crystallographic orientation at each dispersed particle, and, for a particular morphology an equation relating roughness characteristics such as the average radius of the particles, to the electrochemical parameters of the reaction undergoing at the electrodispersed metal overlayers [16-18].

An illustrative example about the influence of the electrocatalyst roughness on a particular electrochemical reaction, is given by recent data on the voltammetric electrooxidation in acid solution of adsorbed $\mathrm{CO}$ on $\mathrm{Pt}$ overlayers of the same morphology, as determined through STM, and varying roughness factors[19]. This reaction was investigated in the absence of $\mathrm{CO}$ readsorption from the solution, and the adsorbate preparation and its subsequent electro- 
oxidation were made exactly under the same conditions in order to determine exclusively the roughness factor influence on the electrochemical process (Fig. 1). In this case, when the roughness factor changes from 1.9 to 160 the electrooxidation current peak of adsorbed $\mathrm{CO}$ located at $0.6-0.8 \mathrm{~V}$, shifts towards lower positive potentials, and simultaneously the initial voltammetric complexity of peaks tends to smear out. Most of these effects are due to the influence of the electrocatalyst particle size on the electrooxidation of $\mathrm{CO}$ adsorbate, which is recognized as a poison in the catalytic electrooxidation of various organic fuels $[20-22]$.

The present work is a review of the recent advances in the development of metal electrode surfaces with preferred crystallographic orientations and different

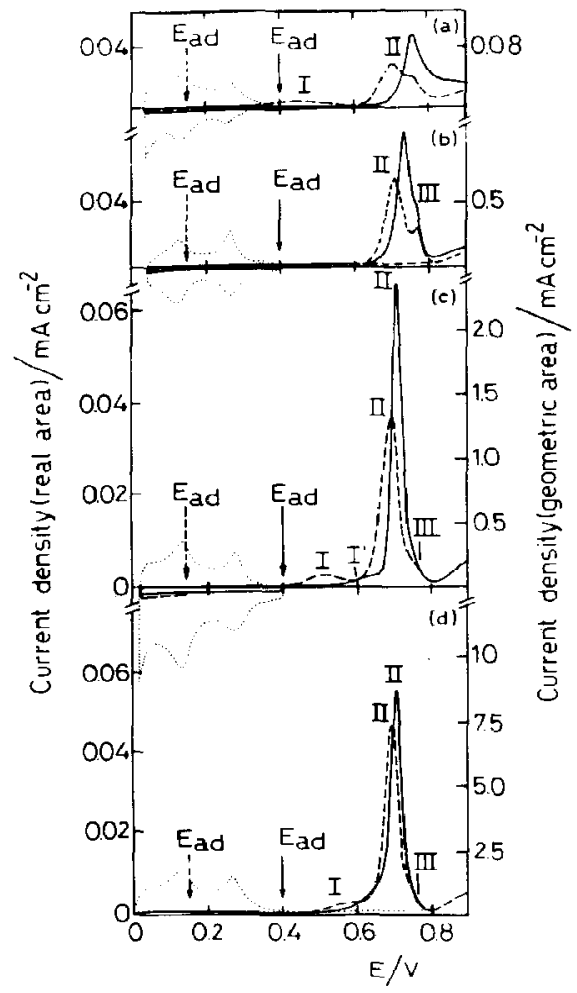

Fig. 1. Voltammograms at $0.01 \mathrm{Vs}^{-1}$ for the electrooxidation of adsorbed $\mathrm{CO}$ on different platinum electrodes in $0.5 \mathrm{M} \mathrm{H}_{2} \mathrm{SO}_{4}$ at $25^{\circ} \mathrm{C}$ under adsorbate saturation coverage. (a) Mirror-polished platinum, $R=1.9$; (b) electrodispersed platinum, $R=5$; (c) electrodispersed platinum, $R=33$; (d) electrodispersed platinum, $R=160$. Dotted lines correspond to blank voltammograms in the $\mathbf{H}$-adatom potential range. Dashed lines correspond to the electrooxidation of the adsorbate accumulated at the adsorption potential $E_{\mathrm{a}}-0.15 \mathrm{~V}$. Solid lines correspond to the electrooxidation of the adsorbate formed at $E_{\mathrm{a}}=0.40 \mathrm{~V}$. The CO electrodesorption peak appears between $0.60 .8 \mathrm{~V}$. The symmetry increases and the peak potential value decreases as $R$ increases. I, I', II, and III denote the components of peak multiplicity. Potentials are referred to the rhe scale. Further details are given in [19]. By permission of Elsevier Science Publishers B.V. roughnesses by methods comprising the application of periodic potential treatments to either single or polycrystalline metal electrodes. The description, which is mainly focused on fcc metals in aqueous electrolytes, also deals with the mechanisms of the electrochemical processes being responsible for those changes in the surface structure of metals, and the possibility of modelling the metal surface morphology from STM data.

\section{THE INFLUENCE OF PERIODIC POTENTIAL TREATMENTS APPLIED TO fcc METAL ELECTRODF SURFACFS IN CONTACT WITH AQUEOUS SOLUTIONS}

The surface of a fcc metal electrode such as $\mathrm{Pt}, \mathrm{Au}$, $P d, R h$, etc, immersed in an aqueous solution either acid or alkaline can be substantially modified in different ways throughout the application of periodic perturbing potentials[23-30]. This treatment, depending on the operating conditions, produces either a change in the distribution of crystal faces, or an increase in the real surface area, or the development of some particular surface morphology, or all these effects simultaneously. The type of predominating change in the surface structure depends principally on the upper $\left(E_{u}\right)$ and lower $\left(E_{1}\right)$ potential limits, the frequency $(f)$ and the symmetry of the periodic perturbing potential (Fig. 2) and to a lesser extent, on the waveform of the periodic potential and the electrolyte composition. This means that by changing adequately $E_{\mathrm{u}}$ and $E_{1}$ with respect to the reference potential $E_{\mathrm{r}}$, the frequency and the symmetry of the perturbing potential-these being the parameters affecting the rates of the reactions and the times $\left(\tau_{u}\right.$ and $\left.\tau_{1}\right)$ spent at $E_{\mathrm{u}}$ and $E_{\mathrm{l}}$-the results of the periodic potential treatment, as far as the modification of the electrode surface structure is concerned, can be considerably different. $E_{\mathrm{r}}$ is a reference reversible potential which can he chosen as the equilibrium potential of either the $\mathrm{Me} / \mathrm{Me}^{z+}$ or $\mathrm{Me} / \mathrm{Me}_{x} \mathrm{O}_{y}$ redox reactions, where $\mathrm{Me}$ denotes a metal atom, $\mathrm{Me}^{z+}$ the $z$-charged metal ion, and $\mathrm{Me}_{x} \mathrm{O}_{z}$ a metal oxide.
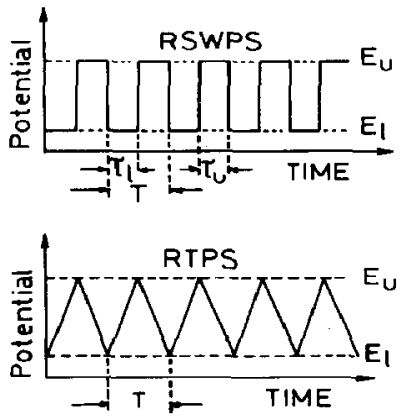

Fig. 2. Typical periodic perturbing potential. RSWPS $=$ repetitive square wave potential scan; $R T P S=$ repetitive triangular potential scan. The period $(T)$, the half-periods $\left(\tau_{1}\right.$ and $\left.\tau_{w}\right)$, and the upper $\left(E_{v}\right)$ and the lower $\left(E_{1}\right)$ potential limits are indicated. 
Let us consider a metal electrode $\mathrm{Me}$ in contact with an aqueous electrolyte, subjected to a square wave perturbing potential. Thus, the main overall reactions occurring during the anodic halfcycle $\left(\tau_{u}\right)$, can be written as follows:

$$
\begin{aligned}
\mathrm{Me}+\mathrm{H}_{2} \mathrm{O}=\mathrm{MeOH}_{\mathrm{ad}}+\mathrm{H}^{+}+\mathrm{e}^{-} \\
\mathrm{MeOH}_{\mathrm{ad}}=\mathrm{Me}^{z+}+(z-1) \mathrm{e}^{-}+\mathrm{OH}^{-}, \\
\mathrm{Me}(\mathrm{OH})_{\mathrm{ad}}+(z-1) \mathrm{H}_{2} \mathrm{O}=\mathrm{Me}(\mathrm{OH})_{2}+(z-1) \mathrm{H}^{+} \\
+(z-1) \mathrm{e}^{-}
\end{aligned}
$$

Reaction (1) behaves as a relatively fast process. The half-life time of the $\mathrm{Me}(\mathrm{OH})_{\text {ad }}$ species for many metals at room temperature, as estimated from triangularly modulated linear potential sweep voltammetry, is about $10^{-3} \mathrm{~s}[31,32]$. Reaction (1) can be considered as the initial stage for either the subsequent metal electrodissolution according to Reaction (2), or the hydrous oxide layer formation as indicated by Reaction (3). Therefore, the parameters of the anodic halfcycle, ie $E_{u}$ and $\tau_{u}$, can be adjusted in order to have a net predominance of either Reactions (1) and (2), or Reactions (1) and (3). In the former case, the anodic process should preferentially imply a metal electrodissolution, whereas for the latter the formation of a hydrous metal oxide becomes favoured.

Otherwise, during the cathodic halfcycle $\left(\tau_{1}\right)$ of the periodic potential treatment characterized by $E_{1}$ and $\tau_{1}$, the electrocrystallization of the metal takes place, in one case through the discharge of soluble $\mathrm{Me}^{z+}$ ions produced in the anodic halfcycle, whereas in the other, it can proceed through the electroreduction of the accumulated hydrous metal oxide layer. The overall process for one cycle can then be described as an electrooxidation/electroreduction reaction at the metal surface promoted by the periodic perturbing potential.

It should be noticed that the occurrence of Reactions (1) (3) implies in addition to the surface processes, the participation of mass transport in solution, and cventually through the hydrous metal oxide layer[33]. In the absence of diffusing species in solution the application of the periodic perturbing potential for values of $E_{u}$ and $E_{1}$ lying above and below $E_{x}$, the equilibrium potential value for the $\mathrm{Me} / \mathrm{Me}^{2+}$ redox couple means that during the anodic halfcycle, ie under $E_{\mathrm{u}}$ and $\tau_{\mathrm{u}}$, the electrode surface becomes a source of $\mathrm{Me}^{\mathrm{z}+}$ ions going into solution, and then the maximum concentration gradient is established between the electrode surface and the bulk of the solution through a distance $\delta_{\mathrm{a}}$, ie the corresponding boundary layer thickness. On the other hand, during the cathodic halfcycle, ie under $E_{1}$ and $\tau_{1}$, the $\mathrm{Me}^{z+}$ ion concentration at the electrode surface falls rapidly to zero, provided that the response of the $\mathrm{Me} / \mathrm{Me}^{2+}$ redox couple is very fast, and in this case, the concentration gradient of $\mathrm{Me}^{z+}$ ions is established through a diffusional boundary layer thickness, $\delta_{c}$, which is certainly much smaller than $\delta_{\mathrm{a}}[34]$ (Fig. 3). For a symmetric perturbing potential the values of $\delta_{\mathrm{a}}$ and $\delta_{\mathrm{c}}$ depend on the square root of the period, $T(T=1 / f)$, whereas for an asymmetric perturbing potential they depend on the square root of either $\tau_{\mathrm{u}}$ or $\tau_{\mathrm{l}}$. In both cases, however, the values of $\delta_{\mathrm{a}}$ and $\delta_{\mathrm{c}}$ which initially depend on $N$, the number of cycles, approach steady values for $N \rightarrow \infty[33]$.
The relationships between $\delta_{\mathrm{a}}$ and $\delta_{\mathrm{c}}$ with $T, \tau_{\mathrm{v}}$ and $\tau_{\mathrm{l}}$ become important to determine the optimal operation conditions for the electrochemical reactions to proceed under a preset kinetic control. Thus, for the case of Pt, symmetric perturbing potentials involving frequencies greater than $1 \mathrm{kHz}$ thereabouts, provide values of $\delta_{\mathrm{a}}$ and $\delta_{\mathrm{c}}$ sufficiently small to assure that the electrochemical process is under surface reaction kinetic control. It should be remembered that the electrochemical reactions occuring at the solid metal surface are coupled to surface diffusion of adatoms $[35,36]$. In this case, the kinetics of Reactions (1) and (2) in both directions depend on the type of crystal face. Furthermore, as the potentials of zero charge of the various crystal faces are different, the proper overpotentials associated with $E_{u}$ and $E_{1}$ should be also different for each crystal face[ $[37,38]$.

Under certain conditions as referred to further on, the periodic potential treatment favours the formation of a thick metal oxide layer. The accumulation of the latter results from the lack of complementary between the anodic and the cathodic processes undergoing under the periodic perturbing potential treatment provoked either for a large anodic overpotential, ie $E_{\mathrm{u}}>2.0 \mathrm{~V}$ (vs rhe) (see Section 4 ) or a large $\tau_{\mathrm{u}} / \tau_{1}$ ratio at a constant $f$ (see Section 7). Furthermore, for a relatively large value of $f$, the oxide layer formation through Reactions (1) and (3) should produce a local acidification which can persist at the growing oxide layer even for high positive applied potentials, due to the slowness in proton migration outward provoked by the shielding effect of the anions adjacent to the metal surface. Under these conditions those equilibria involving $\mathrm{Me}^{z+}$ and $\mathrm{MeOH}$ species can be favoured[39], and thus should assist the formation of a hydrous $\mathrm{Me}(\mathrm{OH})_{2}$ layer. However, for a prolonged anodic half-period of the periodic potential treatment $\left(\tau_{u} \rightarrow \infty\right)$ in acid solution, such as aqueous $\mathrm{H}_{2} \mathrm{SO}_{4}$, the local increase in the acid concentration can promote the formation of passive-type metal oxide layers throughout the increasing dehydrating properties of the more concentrated acid. It should be noticed that for fcc noble metals practically no thick oxide layer can be accumulated under constant potential conditions, in contrast to the results obtained through the application of fast perturbing potentials under adequate conditions.

When the periodic potential treatment accumulates a hydrous metal oxide layer, then the boundary conditions for diffusional processes involving ions and solvent molecules also change. Thus, the mass transport of $\mathrm{H}_{2} \mathrm{O}$ and $\mathrm{Me}^{2+}$ ions in those layers correspond principally to unidirectional diffusion and migration within a growing gel-like structure. The latter is confined in the space comprised between the metal surface and the oxide-solution interface planes.

\section{THE ELECTROCHEMICAL DEVELOPMENT OF PREFERRED CRYSTALLOGRAPHIC ORIENTATION}

The electrochemical development of preferred crystallographic orientation (pco) is related to the electrochemical facetting of metals[25]. Let us consider a polycrystalline $\mathrm{Pt}$ electrode immersed in $1 \mathrm{MH}_{2} \mathrm{SO}_{4}$. 


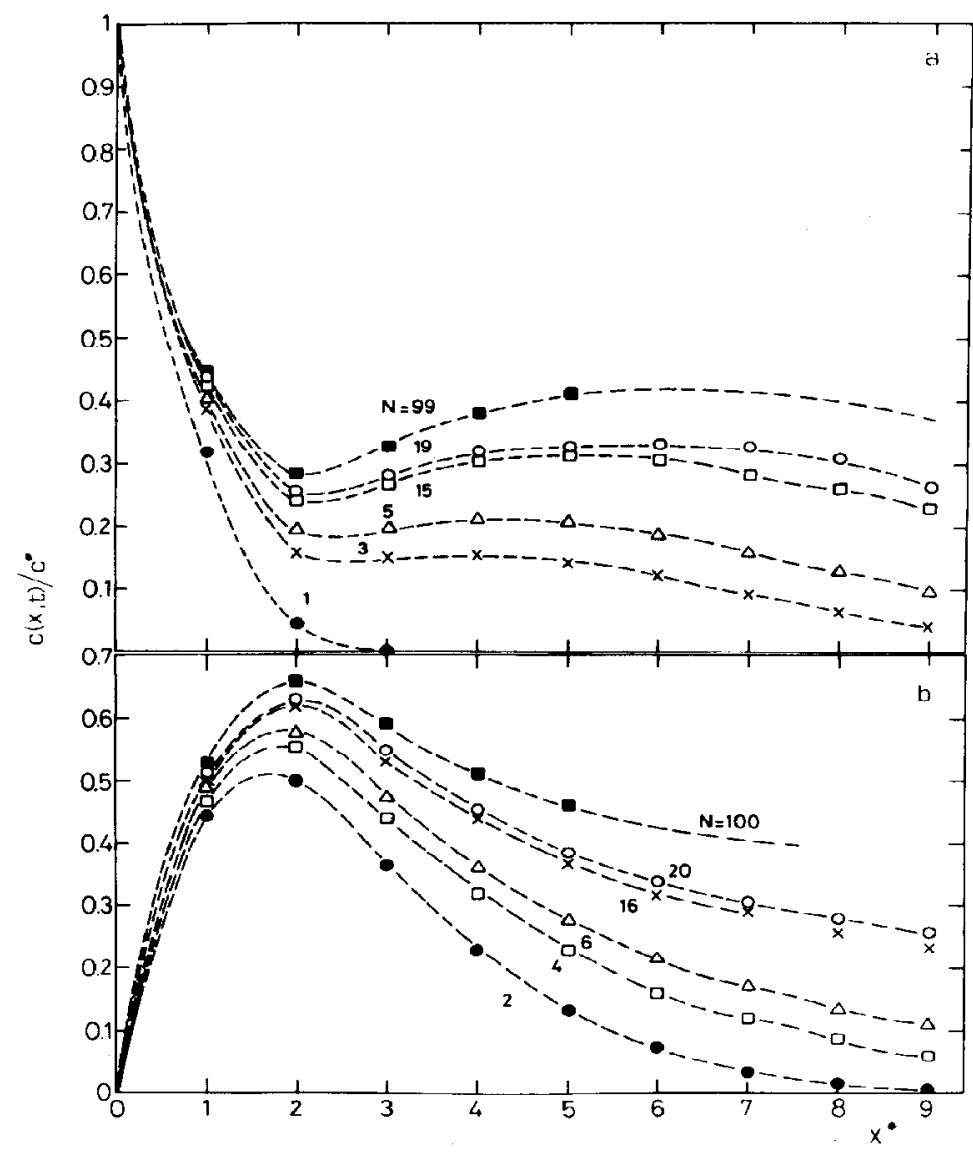

Fig. 3. Dimensionless concentration profiles perpendicular to a plane electrode surface related to the reversible electrodissolution (a) and electrodeposition (b) for the $\mathrm{Me} / \mathrm{Me}^{{ }^{+}}$couple in the absence of $\mathrm{Me}^{\mathrm{z}+}$ species in solution for $t=0$. N corresponds to the number of anodic and cathodic half-cycles. Different profiles for the anodic and cathodic reactions can be observed as well as their dependenee on $N$.

When the conditions of the periodic perturbing potential are such $\left(E_{\mathrm{u}}=1.40 \mathrm{~V} ; E_{1}=0.05 \mathrm{~V} ; f=2.5 \mathrm{kHz}\right)$ (Fig. 4) that exclusively Reactions (1) and (2) proceed, the changes in the morphology of the Pt surface, as followed throughout STM images[40], clearly indicate an initial smoothing stage, followed by the nucleation of $3 \mathrm{D}$ facets, and finally the development of a corrugated structure with flat domains at the atomic level. This type of corrugation, as seen through STM, is comparable to that obtained from $\mathrm{Pt}$ single crystal surfaces subjected to voltammetric potential cycling[41]. The pco Pt surface obtained under these conditions exhibits practically no change in roughness as compared, for instance, to a mirror-like polished $\mathrm{Pt}$ surface.

In the case of Pt, the degree of development of pco at the treated surface can be followed through the ratio between the height of strongly adsorbed $H$-electrooxidation current peak at $c a 0.25 \mathrm{~V}$ (vs rhe) and the height of weakly adsorbed $\mathbf{H}$-electrooxidation current peak at ca $0.12 \mathrm{~V}$ (vs rhe) (Fig. S).

The mechanism of pco for fcc metals has been simulated through 2D Monte Carlo calculations $[42$,
43] for (111)-type pco and (100)-type pco Pt starting from polycrystalline Pt surfaces, by using two variables for each lattice symmetry, one related to the random walk of the $\mathrm{Me}^{2+}$ ion in solution, and another one related to Me atom (adion) surface diffusion (Fig. 6). This model accounts for most of the characteristic features found for the different pco $\mathrm{Pt}$ electrodes in acid solutions. The information derived from the Monte Carlo simulations were also complemented by applying the tight bonding approach to the pco mechanism at metal clusters with different surface configurations[44]. These calculations provided information about the reactivity of the different atoms at the metal cluster surface level when the metal cluster was subjected to oxidation-reduction cycles involving the $\mathrm{Me} / \mathrm{Me}^{\mathrm{z}+}$ redox couple.

\section{THE ELECTROCHEMICAL DEVELOPMENT OF SURFACE ROUGHNESS}

The electrochemical development of roughness at metal surfaces such as those of $\mathrm{Pt}, \mathrm{Au}, \mathrm{Rh}, \mathrm{Ag}$, and $\mathrm{Pd}$, 

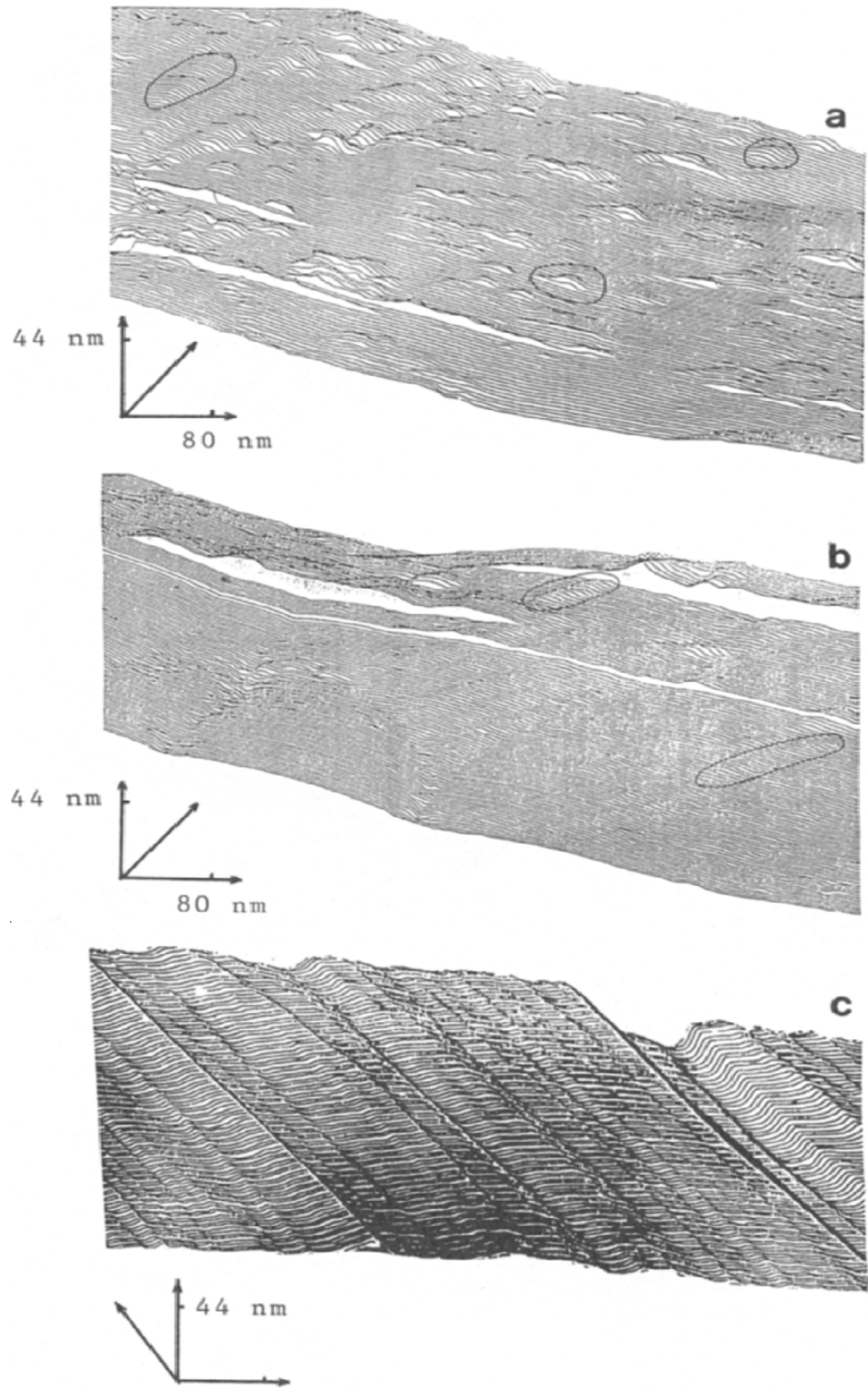

$80 \mathrm{~nm}$

Fig. 4. STM images of the development of electrochemical facetting at a pc platinum electrode by means of a repetitive square wave potential signal $\left(E_{1}=0.05 \mathrm{~V}\right.$ (vs rhe), $E_{\mathrm{u}}=1.4 \mathrm{~V}, f=2.5 \mathrm{kHz}$ and variable times) in $1 \mathrm{M} \mathrm{H}_{2} \mathrm{SO}_{4}, 25^{\circ} \mathrm{C}$. The initial stage shows the surface smoothing and the appearance of growing centers related to facetting (a). On increasing duration of the treatment, the initiation of formation of parallel ridges can be noted (b) which afterwards results in a clear development of the stepped surface topography (c). 

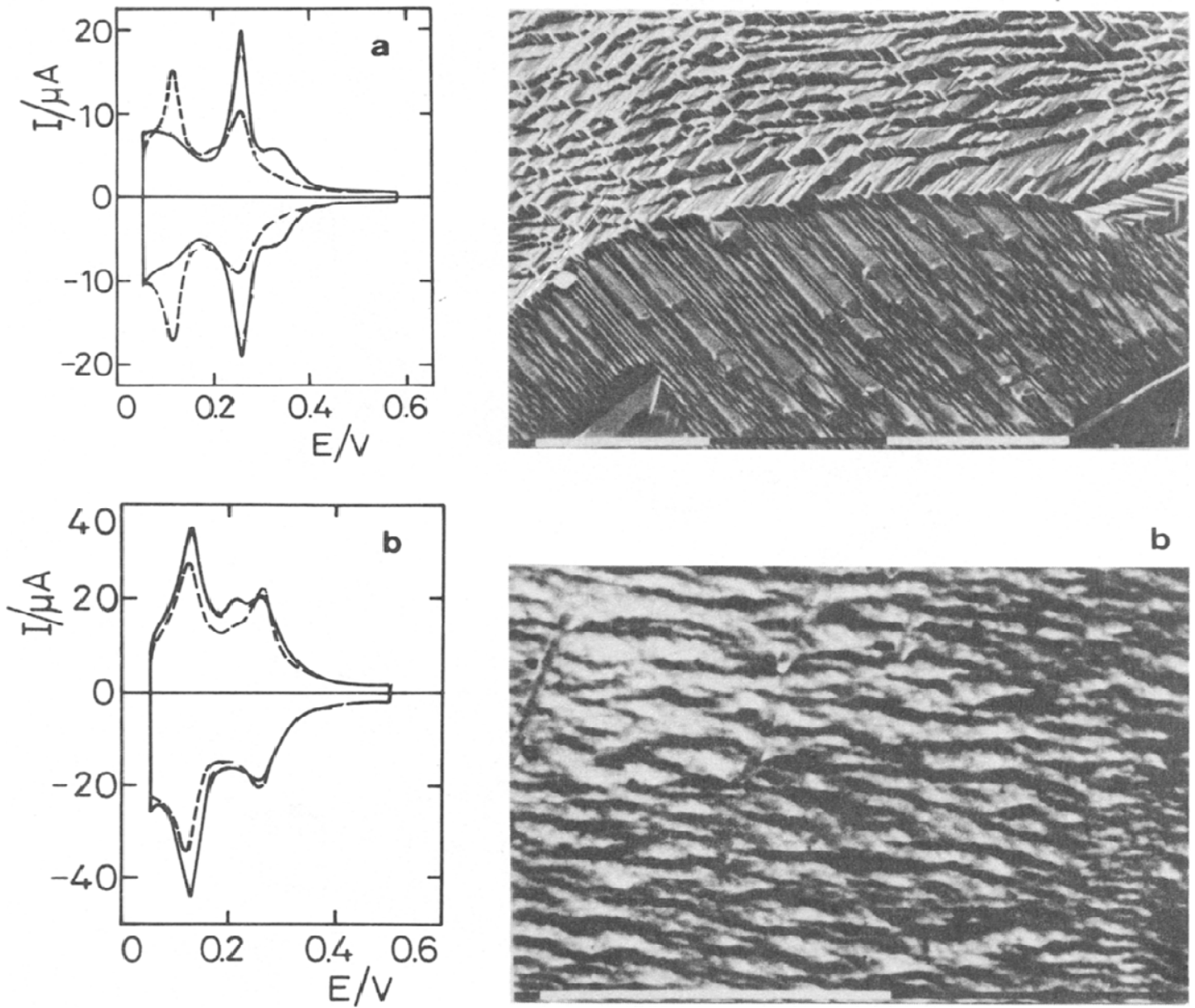

b

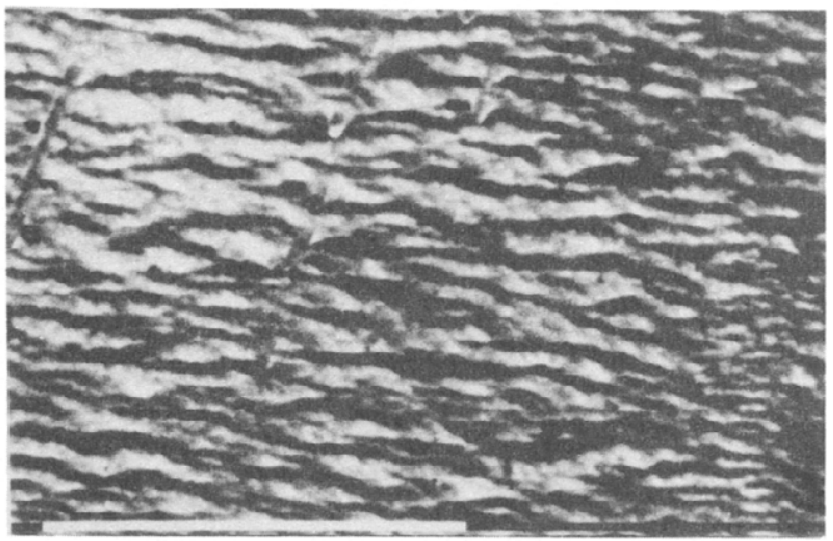

Fig. 5. Voltammograms and SEM micrographs of (100)-type pco platinum (a) and (111)-type pco platinum (b). Scale: $10 \mu \mathrm{m}$. Voltammograms run at $0.1 \mathrm{~V} \mathrm{~s}^{-1}$ in $1 \mathrm{M} \mathrm{H}_{2} \mathrm{SO}_{4}$ at $25^{\circ} \mathrm{C}$. Dashed traces correspond to the pc starting platinum. Solid lines correspond to the pco platinum electrodes. Potentials are referred to rhe. Apparent geometric electrode area: $0.1 \mathrm{~cm}^{2}$.

results from the following procedure involving two successive stages. Firstly, a periodic perturbing potential, ie a square wave potential scan with preset $E_{\mathrm{u}}, E_{\mathrm{l}}$, $f$, and $\tau_{\mathrm{u}} / \tau_{1}$ values, is applied to a metal electrode to accumulate a hydrous metal oxide layer on the electrode surface. Secondly, the hydrous metal oxide layer is electroreduced under either a slow potential sweep or a potential step, the electroreduction conditions being adjusted to assure the formation of a rough metal overlayer $[16,17,45,46]$. Both stages are essential to attain metal overlayer structures with reproducible roughness factors ranging from $2-10^{3}$. The increase in active surface area $(R)$ of the resulting metal overlayer can be voltammetrically followed by comparing either the corresponding $\mathrm{H}$-adatom or $\mathrm{O}$ adatom monolayers before and after the application of the perturbing potential. The $\mathbf{H}$-adatom monolayer charge can be used to evaluate the roughness of both $\mathrm{Pt}$ and $\mathrm{Rh}$ overlayers, whereas the $\mathrm{O}$-adatom mono- layer charge becomes useful to define the roughness of both $\mathrm{Au}$ and Pd overlayers.

The useful ranges of the symmetric periodic square wave potential parameters for the hydrous metal oxide layer formation on $\mathrm{Pt}, \mathrm{Rh}$, and $\mathrm{Au}$ in $1 \mathrm{MH}_{2} \mathrm{SO}_{4}$ at $25^{\circ} \mathrm{C}$ are the following. $\mathrm{Pt}$ : $2.0 \mathrm{~V} \leqslant E_{u} \leqslant 2.8 \mathrm{~V} ; \quad-0.3 \mathrm{~V} \leqslant E_{1} \leqslant 0.5 \mathrm{~V} ; \quad 0.5 \mathrm{kHz} \leqslant$ $f \leqslant 10 \mathrm{kHz}$. Rh: $1.9 \mathrm{~V} \leqslant E_{\mathrm{u}} \leqslant 2.3 \mathrm{~V} ; \quad-0.1 \mathrm{~V} \leqslant E_{1} \leqslant$ $0.1 \mathrm{~V} ; \quad 0.5 \mathrm{kHz} \leqslant f \leqslant 6 \mathrm{kHz}$. Au: $2.1 \mathrm{~V} \leqslant E_{\mathrm{u}} \leqslant 3.0 \mathrm{~V}$; $0.2 \mathrm{~V} \leqslant E_{1} \leqslant 1.1 \mathrm{~V} ; 1.0 \mathrm{kHz} \leqslant f \leqslant 10 \mathrm{kHz}$. Potentials are referred to the rhe in the same electrolyte. Likewise, the corresponding conditions for the electroreduction stage are as follows. Pt: RTPS at $v \simeq 0.07 \mathrm{Vs}^{-1}$ or at a constant potential step, $E_{\mathrm{s}} \simeq 0.3 \mathrm{~V}$. Rh: RTPS at $v \simeq 0.04 \mathrm{~V} \mathrm{~s}^{-1}$ or at $E_{\mathrm{s}} \simeq 0 \mathrm{~V}$ Au: RTPS at $v>0.1 \mathrm{Vs}^{-1}$ or at $E_{\mathrm{s}}<0.5 \mathrm{~V}$. Let us now consider the possible mechanism related to the hydrous oxide layer electroformation, and the mechanism which can explain the electroreduction of the accumu- 
$a_{1}$
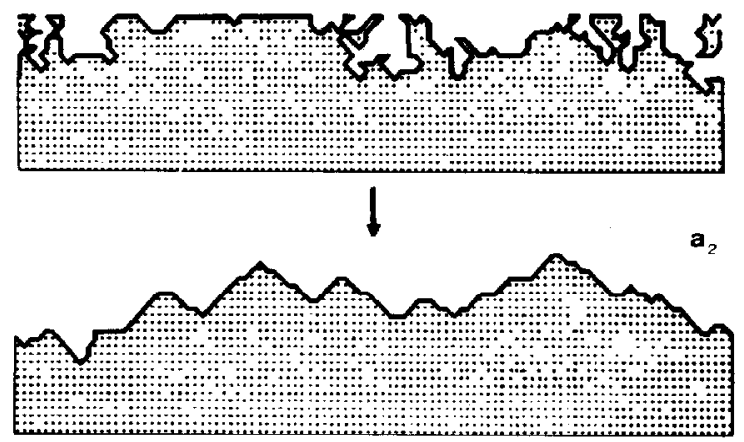

$\mathbf{b}_{1}$

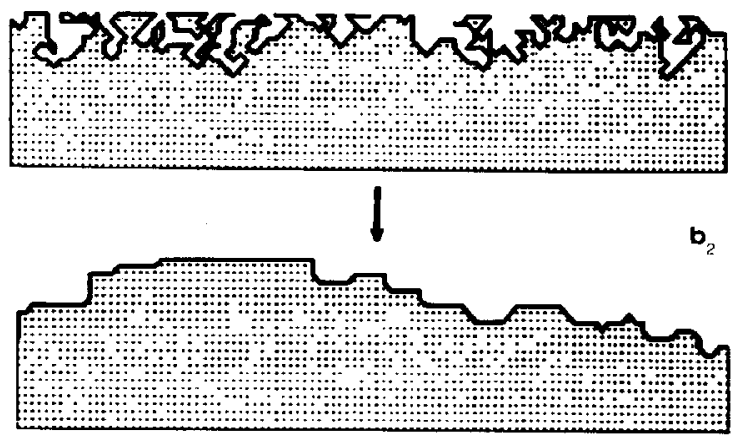

Fig. 6. Montecarlo simulation of electrochemical facetting starting from an irregular array of atoms at the border $\left(a_{1}\right.$ and $b_{1}$ ). The development of the 2-D pco in $a_{2}$ and $b_{2}$ can be assimilated to the profiles of (111)-type pco faces and (100)type pco faces, respectively. Further details about the calculation procedures can be seen in references $[42,43]$.

lated hydrous oxide layer yielding the rough metal overlayers.

\subsection{The accumulation of the hydrous metal oxide layer}

The formation of the hydrous metal oxide layer is, in principle, similar to that already described in Section 2 for the development of pco of metals via oxygen surface containing species, although in the former case the useful potential range for $E_{u}$ is much larger than that found for the achievement of pco effects. Furthermore, the gel-like characteristics of the accumulated metal oxide layer seems to be maintained within the entire range of useful $E_{u}$ values. This means that the prevailing structure is always that of the $\mathrm{Me}(\mathrm{OH})_{z} \cdot x \mathrm{H}_{2} \mathrm{O}$ type without formation of a real passivating oxide layer. This fact has already been explained in Section 2 through the slowness of proton migration from the growing oxide layer outwards at the potential $E_{u}$ and time $\tau_{\mathrm{u}}$ due to the proper electric field generated by anions at the metal-oxide interface which counterbalance the positive potential drop at the interface. This effect can persist even at the poten- tial $E_{1}$ and time $\tau_{1}$ provided that the value of $E_{1}$ be set more positive than the potential of zero charge of the metal. Furthermore, for halfcycles of short duration, the diffusion length of $\mathrm{H}_{2} \mathrm{O}$ molecule within the oxide layer becomes small to produce significant changes in its local concentration.

\subsection{The electroreduction stage of the hydrous metal oxide layer}

The electroreduction of the hydrous metal oxide layer yielding the rough metal overlayer results from an overall reaction such as:

$$
\mathrm{Me}(\mathrm{OH})_{z} \cdot x \mathrm{H}_{2} \mathrm{O}+z \mathrm{e}^{-}=\mathrm{Me}+z \mathrm{OH}^{-}+x \mathrm{H}_{2} \mathrm{O}
$$

occurring relatively fast at potentials more negative than the value of $E_{\mathrm{r}}$. Reaction (4) actually involves a phase change from the hydrous metal oxide (phase I) to the metal overlayer (phase II)[45]. In principle, such a process admits two extreme limiting situations, namely, either an electroreduction involving the largest possible change in the volume in going from the initial to the final state, furnishing a compact metal overlayer, or an electroreduction proceeding at approximately constant volume conditions. The latter means the development of a non-uniform metal overlayer with certain type of voids which in turn become available holes to be filled with the solution phase.

In order to understand the mechanism of the metal oxide layer electroreduction, let us assume that the hydrous metal oxide phase is made of $\mathrm{Me}^{2+}, \mathrm{H}^{+}$and $\mathrm{OH}^{-}$ions, other ions from the electrolyte, and solvent molecules, all confined within the hydrous oxide layer volume. The latter is defined by the electrode geometric area times the average thickness of the hydrous metal oxide layer. Therefore, in dealing with the electroreduction process one can distinguish the following stages occurring simultaneously: (i) The shift of $\mathrm{Me}^{z+}$ from phase I to the metal surface; (ii) the incorporation of $\mathrm{Me}^{z+}$ into phase II through the addition of the $z \mathrm{e}^{-}$charge to the conduction band of the metal; (iii) the transport of ions and $\mathrm{H}_{2} \mathrm{O}$ within the oxide layer. The transport of ions should occur either through migration when the applied potential is different from the potential of zero charge, or through diffusion when both potentials are equal. Likewise, the transport of $\mathrm{H}_{2} \mathrm{O}$ molecules should mainly occur through diffusion in the oxide layer. Therefore, the value of the electroreduction potential should play an important role in the metal overlayer growth in different ways: (i) by assisting the mobility of $\mathbf{M e}^{z+}$ ions from phase I to phase II; (ii) by influencing the shift of the $\mathrm{Me}^{\mathrm{z}}$ adion at the metal plane to reach a definite position at the metal lattice. The relative contribution of (i) and (ii) can determine the morphology of the metal overlayer, ie smooth surface, brush-like structures, sticking spherical super-clusters, conical-shaped domains, etc [47]. It is interesting to mention that in the case of $\mathrm{Pt}$ and $\mathrm{Au}$, roughness factors of the grown metal overlayers ranging from about 2 to near $10^{3}$ are obtained, dependent on the electroreduction conditions $[16,17]$.

The structure of the hydrous metal oxide layer consists at least of two distinguishable layers, namely, the inner layer in contact with the metal which involves a charge in the order of a few monolayers, and 
the outer layer, the thickness of the latter depending on the duration of the periodic perturbing potential treatment. The hydrous nature of the outer layer is consistent with the low value of the real part of the refractive index derived from ellipsometric data[48]. The latter parameter, however, increases slowly with time, as it should be expected for an oxide layer whose content of $\mathrm{H}_{2} \mathrm{O}$ decreases progressively although slowly by holding the metal/oxide layer system at either open circuit potential or at a constant applied potential in the vicinity of $E_{n}$.

4.2.1. Electroreduction of the hydrous metal oxide layer at a constant potential. The current transients resulting for the electroreduction of the hydrous oxide layers of $\mathrm{Pt}$ and $\mathrm{Au}[45,46]$ at a constant potential consist of two main contributions, namely, the electroreduction processes of the inner and outer parts of the hydrous metal oxide layer. The current transients obtained for the growth of Pt and Au overlayers from the hydrous metal oxide layers at different potential steps, $E_{\mathrm{s}}$ (Figs $7 \mathrm{a}-\mathrm{c}$ ), involving a constant amount of hydrous metal oxide prepared exactly under the same conditions, show that the more negative $E_{\mathrm{s}}$, the shorter the time required to complete the electroreduction process. Likewise, for a relatively small hydrous metal oxide layer charge, each current transient exhibits a current density maximum, $j_{\mathrm{M}}$, at the time $t_{\mathrm{M}}$. Likewise as $E_{\mathrm{s}}$ is set more positive, $j_{M}$ increases and $t_{M}$ decreases. The initial rapid current decay occurring for $t<1 \mathrm{~s}$, related to the electroreduction of the inner oxide monolayer, can be interpreted in terms of an adsorption-desorption process governed by a nucleation and growth mechanism[49]. In this case, phase I is the oxide monolayer considered as a random phase related to the adsorption-desorption process, and phase II is the ordered metal phase.

The phenomenological relationships derived from the current transients for the electroreduction of the outer hydrous metal oxide layers, furnish a dependcnce of $j_{M}$ on $E_{\mathrm{s}}$ (Fig. 7d) which appcars to bc independent of the initial hydrous metal oxide charge density, although it exhibits two regions, one comprised between 0.4 and $0.6 \mathrm{~V}$ ( $v s E_{\mathrm{r}}$ ), which corresponds to an exponential increase of $j_{M}$ with $E_{s}$, and another one for $E_{\mathrm{s}}>0.62 \mathrm{~V}$, where $j_{\mathrm{M}}$ becomes independent of $E_{\mathrm{s}}$. Hence the $j_{\mathrm{M}}$ vs $E_{\mathrm{s}}$ dependence indicates that the kinetics of the electroreduction process changes at $E_{\mathrm{s}} \simeq 0.62 \mathrm{~V}$, from an activation rate control for $E_{\mathrm{s}}<0.62 \mathrm{~V}$, to a mass transport rate control, for $E_{\mathrm{s}}>0.62 \mathrm{~V}$.

Otherwise, for $E_{\mathrm{s}}>0.62 \mathrm{~V}$, and at any hydrous metal oxide charge density, $q$, one observes a linear increase of $R$ with $q$ with a $\Delta R / \Delta q$ slope equal to $62.5 \mathrm{~cm}^{2} \mathrm{C}^{-1}$. But for $E_{\mathrm{s}} \simeq 0.40 \mathrm{~V}$, the value of $R$ attains a constant value equal to 1.8 . On the other hand, the shape of the peaked current transients resulting for the electroreduction of the outer hydrous metal oxide layer is consistent with a nucleation and growth mechanism involving 3-D pyramids under charge transfer control, where diffusion of reacting species to growing sites is essential for further expansion [50].

Finally, the current transients resulting for the electroreduction of relatively thick hydrous gold oxide layers at large negative values of $E_{\mathrm{s}}$, show a current
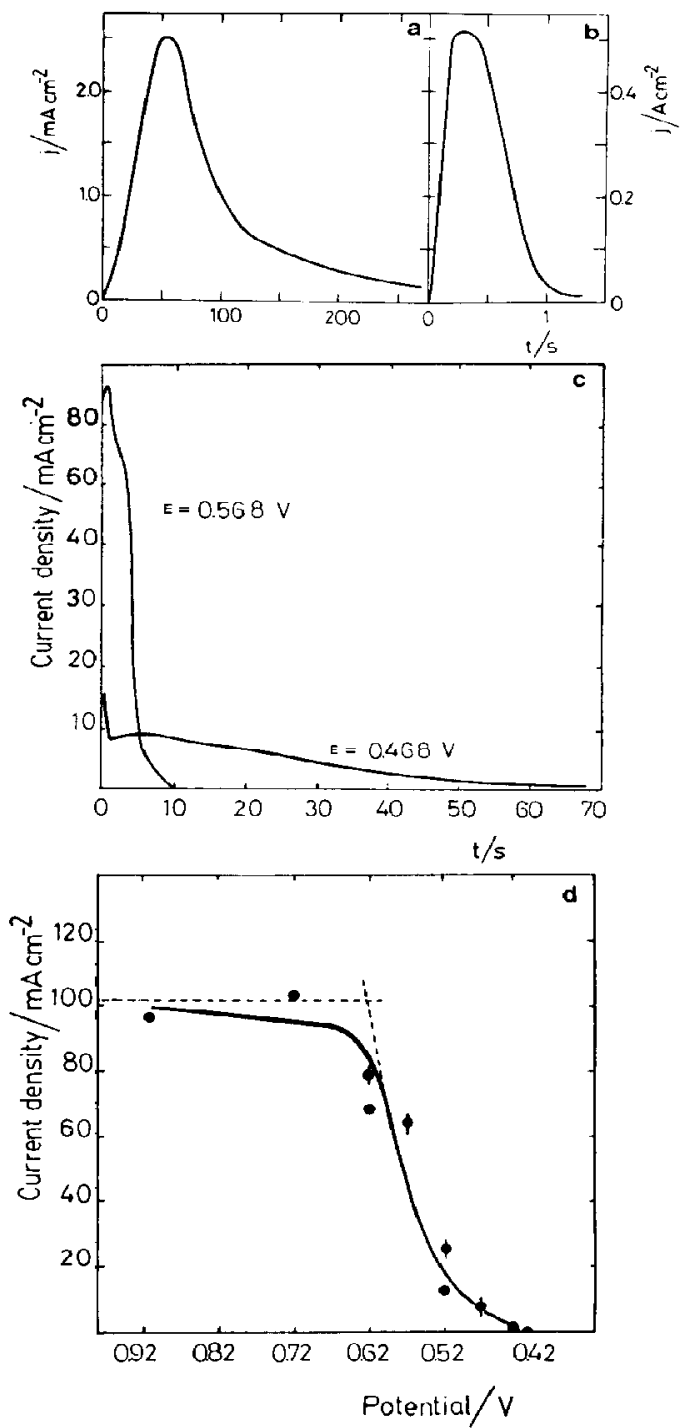

Fig. 7. Current transient data. Potentiostatic electroreduction current transients for hydrous platinum oxide layers in $0.5 \mathrm{M} \mathrm{H}_{2} \mathrm{SO}_{4}$ at $25^{\circ} \mathrm{C}$. (a) Electroreduction potential $E$ $=0.27 \mathrm{~V}$; (b) $E=0 \mathrm{~V}$. The values of $E$ are referred to the rhe scale. (c) Current transients related to the potentiostatic electroreduction of hydrous gold oxide layer at different $E$ values. (d) Dependence of the peaked current density on electroreduction potential for hydrous gold oxide layers. This plot shows two regions, one exhibiting a Volmer-Tafel line relationship, and another one where the current becomes potential independent. Potentials in (c) and (d) are defined as $E_{\mathrm{r}}-E$, where $E_{\mathrm{r}}$ is the reversible potential of the $\mathrm{Au} / \mathrm{Au}_{2} \mathrm{O}_{3}$ couple.

plateau which obeys a mass transport controlled kinetics, which can be attributed to the shift of $\mathrm{OH}^{-}$ ions moving through the oxide layer outwards. In this case, the reaction resistance depends on the $\Delta c_{\mathrm{OH}}-/ \delta_{\text {ox }}$ ratio, ie the concentration gradient of $\mathrm{OH}^{-}$ions 
through $\delta_{\text {ox }}$, the hydrous oxide layer thickness. The mass transport kinetic control disappears as the value of $\delta_{\text {ox }}$ attains a value sufficiently low, so that the kinetic control is switched to the nucleation and growth mechanism involving the depletion of the reacting species already mentioned, ie as the death of the electroreduction process is approached.

\section{STM IMAGING}

Very recently[14] it was possible to obtain Scanning Tunneling Microscopy images of rough Pt surfaces prepared by electroreducing thick hydrous platinum oxide layers (Fig. 8). The morphology of the metal overlayer and the roughness development were explained on the basis of a Pt overlayer geometry consisting of a large number of sticking nearly spherical platinum superclusters of about $10 \mathrm{~nm}$ average diameter. This type of metal overlayers, for the case of $\mathrm{Pt}$ and $\mathrm{Au}$ (Fig. 9), exhibit characteristic electroreflectance spectra[51], and in the case of $\mathrm{Pt}$ interesting electrocatalytic properties for the electrooxidation of different molecules, such as $\mathrm{CO}$ [19], "reduced" $\mathrm{CO}_{2}$ [52], methanol[53] and glucose[54].

A simultaneous SEM and STM imaging[18] allowed for the case of Au overlayers to establish the formation of top dome columnar structures. This geometry involves a value of $R=1.8$ for a closed packed array of hemispherical crystallites, and a value of $R$ which is a function of $q$, the charge involved in the electroreduction reaction, for a columnar overlayer with a beight of about one half the initial hydrous metal oxide layer thickness. The value of $R=1.8$ corresponds to phase I to phase II electroreduction process taking place with the maximum change in volume in going from the initial to the final state, whereas, the dependence of $R$ on $q$ comes out for a phase change process proceeding under a nearly constant volume condition. These results explained satisfactorily the relationships given in Fig. 7 and the features shown in Fig. 9.

The equations derived from the metal overlayer roughness model[18] allow estimation of the following values of $r$, the average radius of the particles at the Au overlayer: $r=12.4 \mathrm{~nm}$ for the columnar growth model and $r=17.7 \mathrm{~nm}$ for the sticking sphere model. These values of $r$ were determined through the STM imaging by working at the nm scale[181. It should be mentioned that STM is the only reliable technique available at present which provides for the first time this basic type of information about the structure of the rough metal overlayers.

\section{POSSIBLE MECHANISM OF ROUGH METAL OVERLAYER ELECTROFORMATION}

The mechanism of the rough metal overlayer electroformation via the hydrous oxide layer electroreduction can be related to nucleation and growth processes comparable to those established for metal electrocrystallization [35]. Furthermore, in the case of Au overlayers, the kinetics of columnar growth can be explained throughout the mechanism advanced recently for columnar growth of metals in the vapour phase [55], where instead of the sticking frequency, a potential dependent sticking coefficient should be used, the latter being expressed in terms of current density[ 18$]$. Thus, for a constant $E_{\mathrm{s}}$ value, it turns out that the roughness factor, $R$, becomes proportional to the square root of $j_{M}$, whereas the radius of the growing column results inversely proportional to the square root of $j_{M}$. For Au overlayers, these predictions are satisfactorily fulfilled, and the electroreduction current transients can be reproduced for a surface
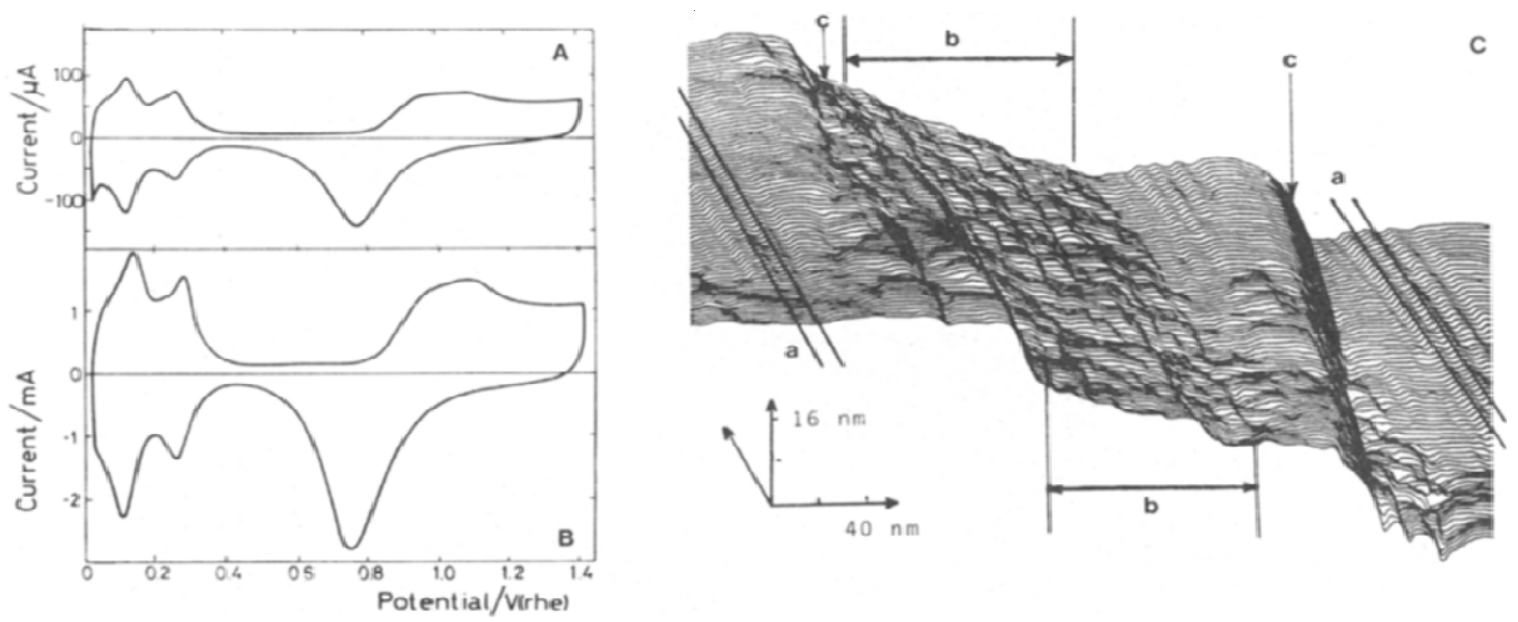

Fig. 8. Voltammograms at $0.3 \mathrm{Vs}^{-1}$ in $0.5 \mathrm{M} \mathrm{H}_{2} \mathrm{SO}_{4}$ at $30^{\circ} \mathrm{C}$ and $\mathrm{STM}$ images of platinum surfaces. (A) Electropolished pe platinum. (B) Electrodispersed platinum $\left(E_{1}=0.4 \mathrm{~V} ; E_{\mathrm{u}}=2.4 \mathrm{~V} ; f=2.5 \mathrm{kHz}\right) ; R=80$; apparent geometric electrode area $=0.10 \mathrm{~cm}^{2}$. Potentials are referred to the rhe scale. (C) STM image of the electrodispersed platinum. Three different topographies can be distinguished: parallel ridges (a), dome-like structures (b) and large steps (c). Regions of type (b) are responsible for the high roughness factor value. 

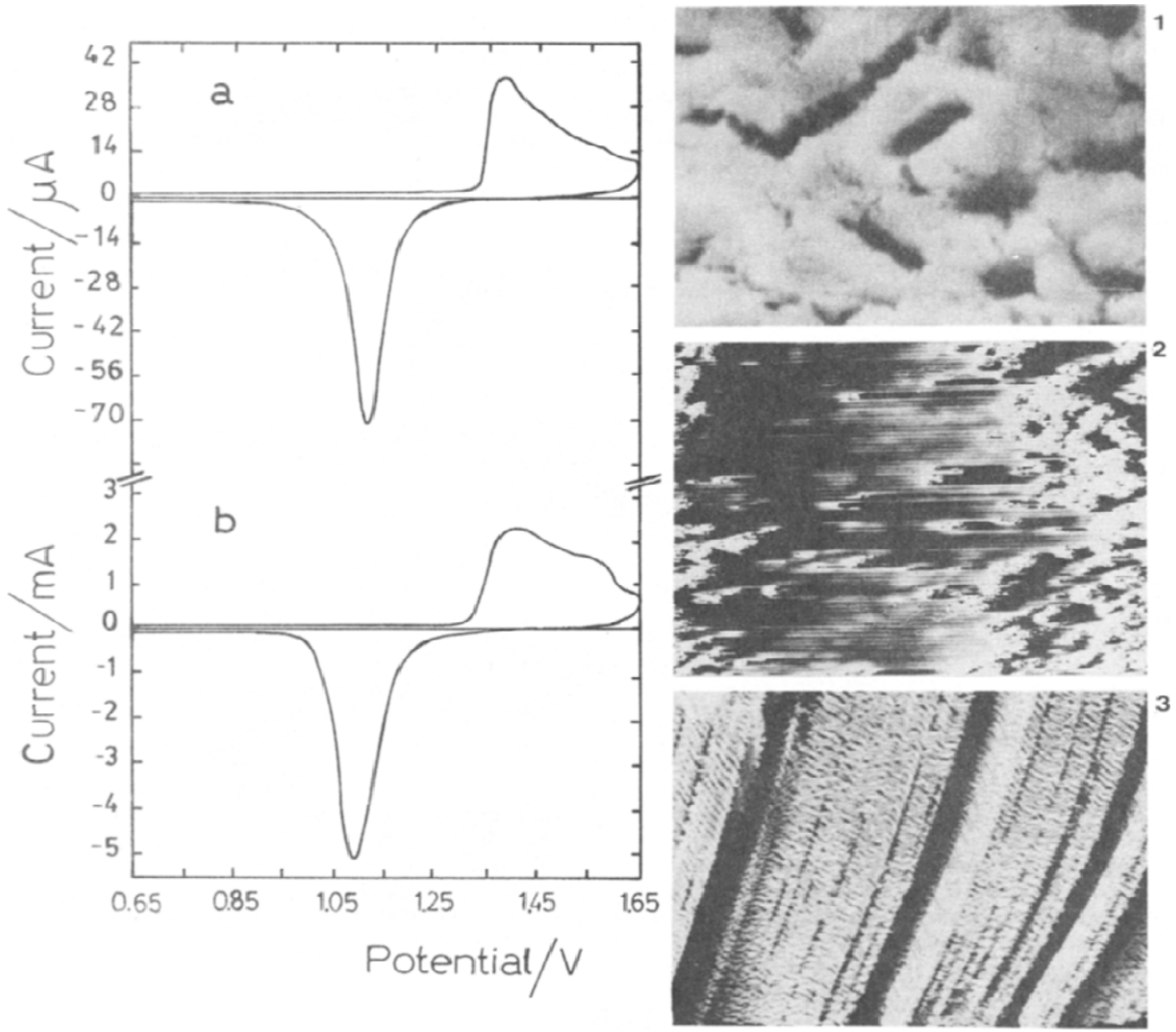

Fig. 9. SEM and STM images and voltammograms of electrodispersed gold $\left(E_{1}=0.6 \mathrm{~V} ; E_{\mathrm{u}}=2.5 \mathrm{~V}\right.$, $f=5 \mathrm{kHz}$ ); apparent geometric electrode area: $1 \mathrm{~cm}^{2} ; R=80$. (1) SEM micrograph, scale $-1 \mu \mathrm{m}$. (2) STM image covering an area of $350 \times 390 \mathrm{~nm}^{2}$. Spherical superclusters of about $10 \mathrm{~nm}$ average diameter can be distinguished. (3) STM image of a single supercluster covering an area of $7.5 \times 9 \mathrm{~nm}^{2}$. A parallel channel-like structure and surface corrugation can be observed. (a) Voltammogram run in $0.5 \mathrm{M} \mathrm{H}_{2} \mathrm{SO}_{4}$ at $25^{\circ} \mathrm{C}$ for a mirror polished gold; (b) voltammogram for electrodispersed gold, $R=80$. Potentials are referred to the rhe scale.

concentration of $\mathrm{Au}$ ions in the hydrous metal oxide layer, $c_{\text {ion }}=7 \times 10^{-7} \mathrm{~g} \mathrm{~cm}^{-2}$, and a surface diffusion coefficient of Au adions being equal to $10^{-11} \mathrm{~cm}^{2} \mathrm{~s}^{-1}$. This value of the surface diffusion coefficient of $\mathrm{Au}$ adions is certainly large, and it explains the fact that the Au overlayer becomes much less stable than $\mathbf{P t}$ overlayers obtained throughout the same procedure.

On the other hand, if one takes into account that there is a potential window where the electroreduction process fits a Volmer-Tafel equation (Fig. 7d), it is possible to obtain a dependence of either $R$ or the radius of the growing particle on the electrochemical kinetic parameters such as the Tafel slope and the exchange current density. The explicit form of these dependences changes according to the geometry assumed for the metal overlayer growth [56].
Due to the fact that the electroreduction of the hydrous metal oxide can be considered as a reversible process with physical kinetic constrains related to the proper nucleation and growth mechanism, it is possible to use also in this case a Monte Carlo simulation to attempt to explain the dependence of $R$ on the electroreduction potential. This simulation has been made by assuming that the starting hydrous metal oxide layer consists of a number of metal ions confined into the oxide layer cage as referred to above more in detail. Then, the kinetics of the electroreduction process involves a diffusion of particles in the hydrous metal oxide layer and its attachment to the growing surface. The attachment process itself should involve at least two distinguishable contributions expressed as an attachment probability, and a probability for the 
particle on the metal surface to relax to a nearest neighbour site[57]. Accordingly, the problem can be dealt with in terms of recent Vicsek's approach for phase growth[58]. The attachment probability is assumed to be the sum of one contribution due to the curvature of surface sites which takes into account the local surface tension, and another one related to the sticking frequency which is potential dependent. By changing the latter it is possible to attempt a 2-D simulation for the change in $R$ with $E_{\mathrm{s}}$ which agrees with the experimental results (Fig. 10).

From the Monte Carlo calculations one can conclude that for $E_{\mathrm{s}}$ values closer to that of $E_{\mathrm{r}}$, the sticking coefficient is low so that a large diffusion path for the
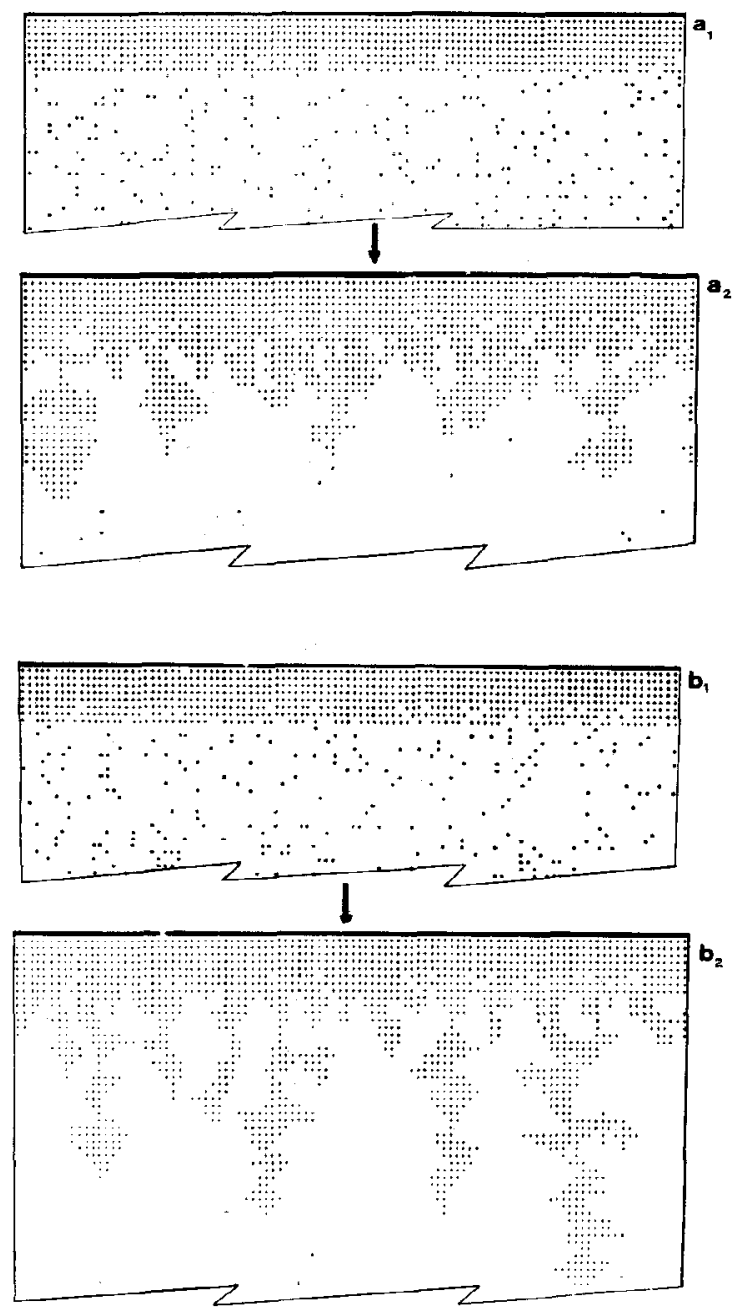

Fig. 10. Montccarlo simulation for the development of a rough surface: $\left(a_{1}\right)$ and $\left(b_{1}\right)$ correspond to the 2-D profile of the starting metal/hydrous metal oxide layer. Development of low rough $\left(a_{2}\right)$ and high rough $\left(b_{2}\right)$ 2-D profiles by attachment of particles from the hydrous metal oxide layer to the high density face (metal). Further details can be seen in [47]. moving particle is involved hefore its incorpnration to the metal atom array. Hence, no voids or pores at the metal overlayer can be produced but a compact structure. Otherwise, as the $E_{\mathrm{s}}-E_{\mathrm{r}}$ potential difference increases, the rate of the interfacial reaction becomes larger, the $j_{M}$ vs $E_{\mathrm{s}}$ relationship approaches the Volmer-Tafel relationship, and correspondingly, the surface diffusion path decreases. In this range of $E_{\mathrm{s}}$, $R$ becomes a function of $E_{s}$. Finally, for very large negative $E_{\mathrm{s}}-E_{\mathrm{r}}$ values a depletion of metal ion concentration at the growing centers takes place, the kinetics of the overall process becomes mass transport control, and the diffusion path of the moving particles to the surface results considerably small. The metal overlayer produced under these conditions contains metal particles, voids and pores approaching a common average radius. In this case, void formation occurs when the rate of metal particle incorporation to the shadowed regions is smaller than the rate of void formation via growth process. The latter becomes very important as far as the surface structure stability is concerned. As a matter of fact the surface instability implies that after completion of the phase change the void filling rate exceeds the void incorporation rate. Therefore, the value of $R$ becomes both time and temperature dependent. Its decrease in time, which can be followed through STM imaging and voltammetry, probably implies a coalescence mechanism mainly controlled by surface diffusion[56]. This evolution of the surface structure follows a decrease in the surface free energy.

\section{THE DEVELOPMENT OF METAL OVERLAYERS WITH A PARTICULAR SURFACE MORPHOLOGY, ROUGHNESS AND PREFERRED CRYSTALLOGRAPHIC ORIENTATION}

The texture of metal electrodeposits has been an important matter in electrocrystallization and electrodeposition of metals under either galvanostatic and potentiostatic conditions $[59,60]$. However, the methodology described in previous sections allows now to attempt another approach to make for the first time the engineering of a solid metal electrode surface.

In this respect, metal overlayers exhibiting different surface morphologies, with a controlled degree of development of both roughness and pco can be produced by applying periodic potential treatments to fcc metal electrodes under proper operating conditions. Let us consider again the example of $\mathrm{Pt}$ electrodes in acid solutions[26]. Thus, after applying to Pt electrodes a periodic and symmetric square wave potential scan between $E_{1}=0.05 \mathrm{~V}$ and $E_{\mathrm{u}}=1.50 \mathrm{~V}$, that is, under conditions where metal electrodissolution/electrodeposition [Reactions (1) and (2)] becomes predominant, and the formation of any oxide layer can be neglected, Pt overlayers with different selected surface morphologies can be obtained depending on the frequency of the pert urbing potential. Thus, at low $f, e g$ in the $0.025 \mathrm{kHz} \leqslant f \leqslant 0.1 \mathrm{kHz}$ range where $\mathrm{Pt}$ electrodeposition is diffusion controlled, metal overlayers with a dendritic texture, large roughness factor and a minor development of pco can be produced (Fig. 11a). Conversely, at $f$ in the $2 \mathrm{kHz} \leqslant \mathrm{f} \leqslant 7 \mathrm{kHz}$ range, 
a
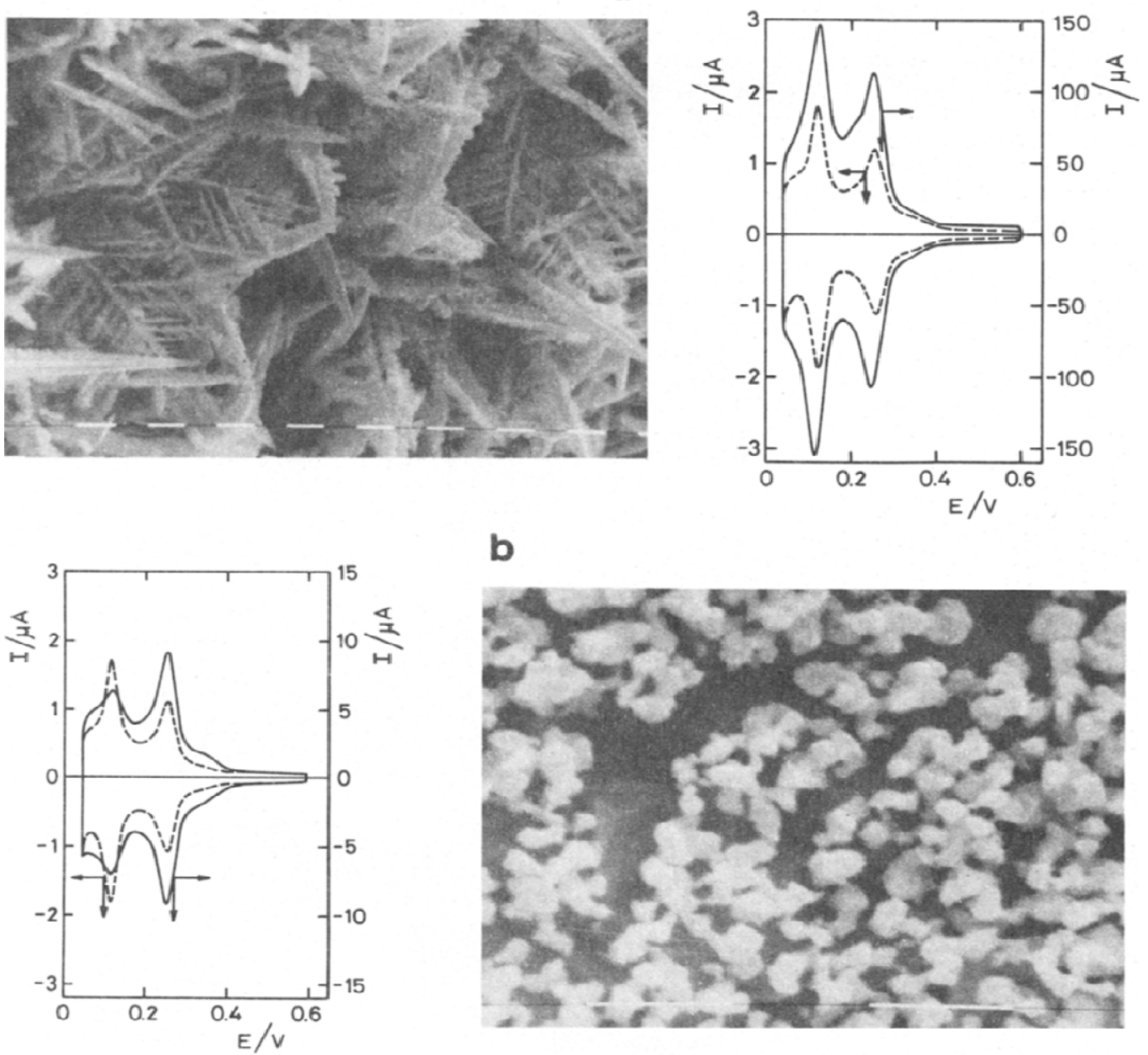

b

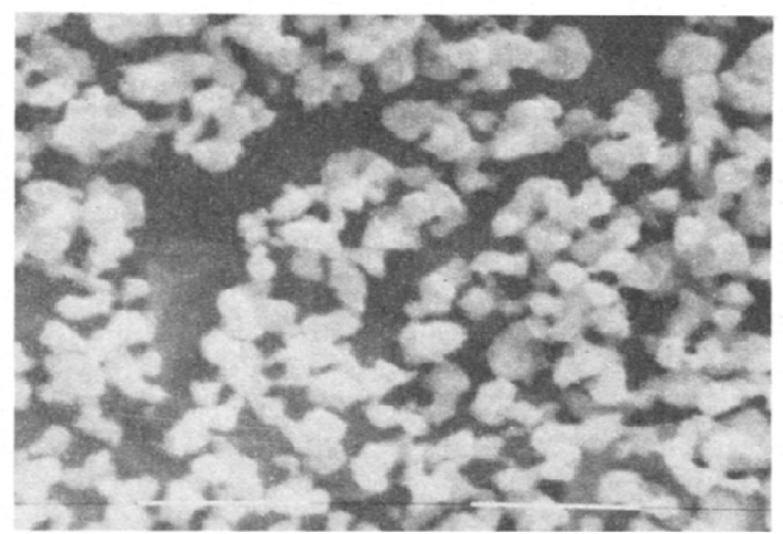

C
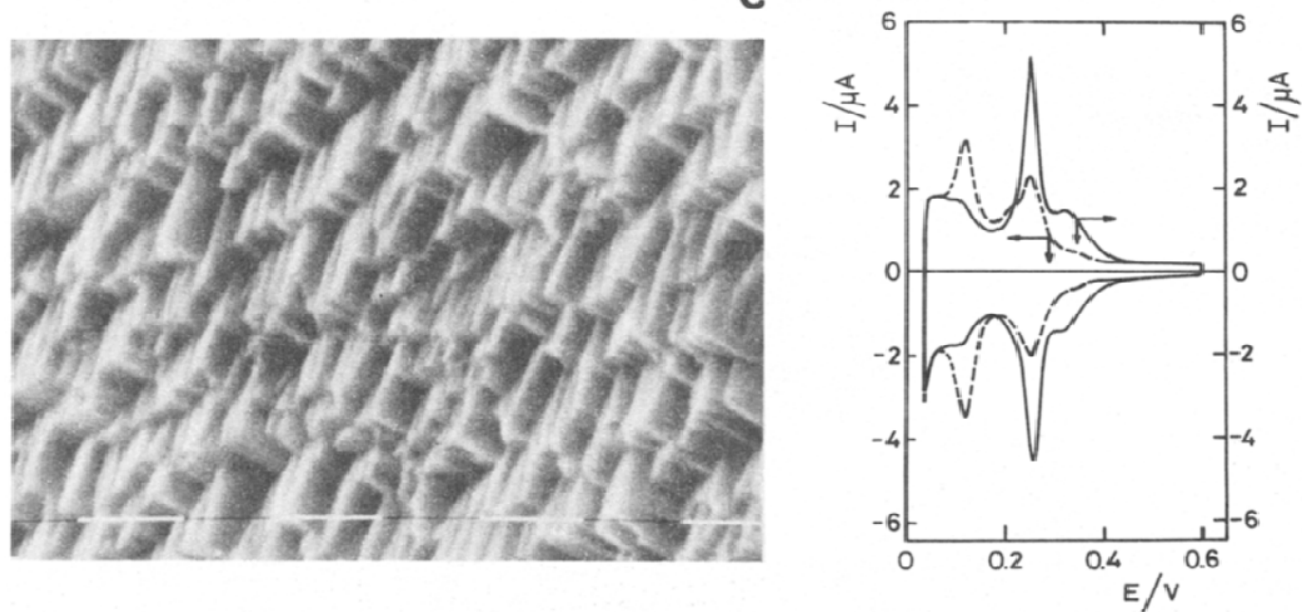

Fig. 11. Voltammograms run at $0.1 \mathrm{~V} \mathrm{~s}^{-1}$ in $1 \mathrm{M} \mathrm{H}_{2} \mathrm{SO}_{4}$ at $25^{\circ} \mathrm{C}$ and SEM micrographs (scale: $1 \mu \mathrm{m}$ ) of platinum surfaces after RSWPS treatment $\left(E_{1}=0.05 \mathrm{~V} ; E_{\mathrm{u}}=1.50 \mathrm{~V}\right)$ at different $f$ : (a) $0.025 \mathrm{kHz}$; (b) $1 \mathrm{kHz}$; (c) $6 \mathrm{kHz}$. Dashed lines correspond to the untreated polyfacetted single crystal platinum spheres. Solid lines correspond to the treated platinum surfaces. Potentials are referred to rhe. Apparent geometric electrode area: $0.015 \mathrm{~cm}^{2}$. 
where the kinetics of the Pt electrodeposition/electrodissolution processes becomes activation controlled, facetted Pt surfaces with a net development of (100)type pco and without an appreciable increase in roughness are obtained (Fig. 11 c). Between these two limiting situations, there is an intermediate $f$ range, ie $0.2 \mathrm{kHz} \leqslant f \leqslant 1 \mathrm{kHz}$, where the kinetics of the overall process changes gradually from diffusion to activation control, this being accompanied by the development of facetted Pt crystallites exhibiting different degrees of development of (100)-type pco and roughness (Fig. 11b).

On the other hand, when Pt electrodes are subjected to either a symmetric square wave perturbing potential between $E_{1}=0.70 \mathrm{~V}$ and $E_{\mathrm{u}}=1.35 \mathrm{~V}$ at $f$ in the order of $\mathbf{k H z}$, or an asymmetric one between $E_{1}=0.05 \mathrm{~V}$ and $E_{\mathrm{u}}=1.50 \mathrm{~V}$ at $0.1 \mathrm{kHz} \leqslant f \leqslant 3 \mathrm{kHz}$, for $\tau_{\mathrm{u}}>\tau_{1}$, the operating conditions correspond to the predominance of Reactions (1) and (3) leading to oxide layers formation. In the former case, brush-like structured Pt overlayers with a large increase in surface roughness and development of the (111)-type pco are formed after some few electroreduction cycles (Fig. 12a). For the latter case, one can observe a critical $\tau_{u} / \tau_{1}$ value which is greater than 1 and decreases on increasing $f$, where thick platinum oxide layers can be produced. These oxide layers after slow electroreduction scans, eg $0.1 \mathrm{~V} \mathrm{~s}^{-1}$, furnish very high rough $\mathrm{Pt}$ overlayers consisting of nearly spherical particle aggregates of about $10 \mathrm{~nm}$ diameter, without any particular pco. However, it should be noticed that there are electroreduction procedures which are able to produce highly rough $\mathrm{Pt}$ overlayers with development of either (100)-type or (111)-type pco[8, 26].

A limiting situation is found when using a symmetric square wave perturbing potential between $E_{1}$ $=0.7 \mathrm{~V}$ and $E_{\mathrm{u}}=1.35 \mathrm{~V}$ at $f$ larger than $6 \mathrm{kHz}$, ie under conditions where metal oxide formation be-

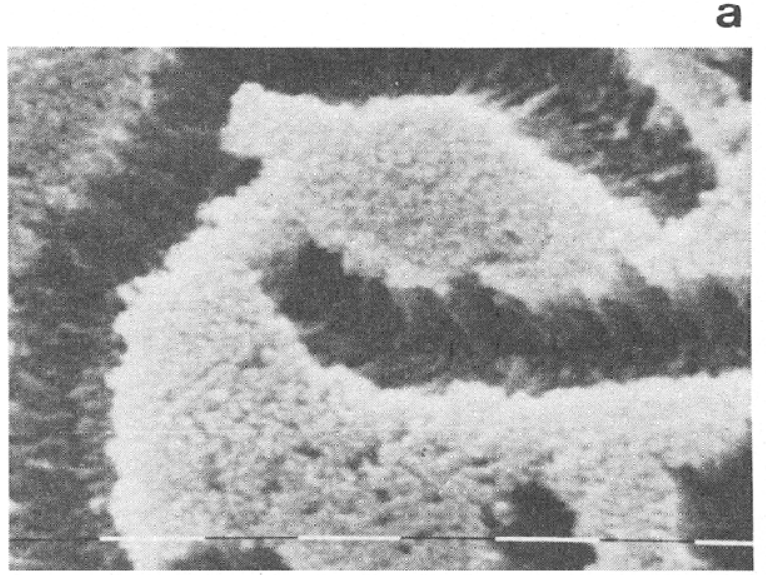

b
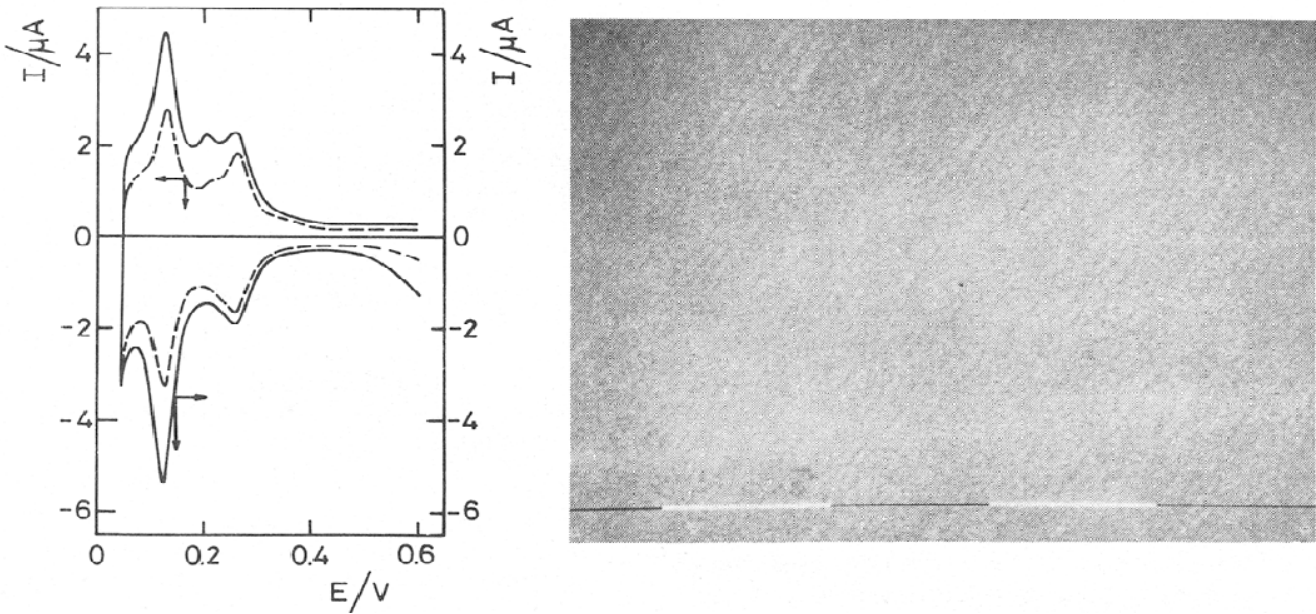

Fig. 12. Voltammograms run at $0.1 \mathrm{~V} \mathrm{~s}^{-1}$ in $1 \mathrm{M} \mathrm{H}_{2} \mathrm{SO}_{4}$ at $25^{\circ} \mathrm{C}$ and SEM micrographs (scale: $1 \mu \mathrm{m}$ ) of platinum surfaces after RSWPS treatment $\left(E_{1}=0.70 \mathrm{~V} ; E_{\mathrm{u}}=1.35 \mathrm{~V}\right)$ at different $f:$ (a) $1 \mathrm{kHz} ;(\mathrm{b}) 7 \mathrm{kHz}$. Dashed lines correspond to the untreated polyfacetted single crystal platinum spheres. Solid lines currespond to the treated platinum surfaces. Potentials are referred to rhe. Apparent geometric electrode area: $0.015 \mathrm{~cm}^{2}$. 
comes unlikely. In this case, Pt surfaces exhibiting a clear development of the (111)-type pco without increase in roughness can be obtained (Fig. 12b).

\section{CONCLUSIONS}

The application of periodic perturbing potentials to fcc metals such as $\mathrm{Pt}, \mathrm{Au}, \mathrm{Rh}$, and $\mathrm{Pd}$, complemented with surface imaging by STM and SEM techniques offers the possibility of attempting for the first time to develop solid electrode surfaces with defined structural characteristics, namely, morphology, type of roughness and degree of pco. The present state of the art in the application of perturbing potential techniques to modify solid electrode surfaces can be summarized in the following scheme:
Acknowledgements-The authors acknowledge the participation in this research work of Prof. Dr A. Baró, Lic. L. Vásquez and Lic. J. Gómez from the Departamento de Fisica, Universidad Autónoma de Madrid, España; of Dr C. Alonso from the Departamento de Quimica, Universidad Autónoma de Madrid, España; of Prof. Dr E. V. Albano and Prof. Dr H. O. Mártin from the Departamento de Física, Universidad Nacional de La Plata, Argentina; and of Prof. Ing. S. L. Marchiano, Dr A. E. Bolzán, Lic. J. C. Canullo, Dr A. M. Castro Luna, Dr C. L. Perdriel, Dr M. E. Vela and Dr A. Visintin from INIFTA, Argentina.

\section{REFERENCES}

1. G. Wedler, Adsorption, Verlag Chemic, Weinheim (1970). 2. J. Bénard (Editor), Adsorption on Metal Surfaces: An

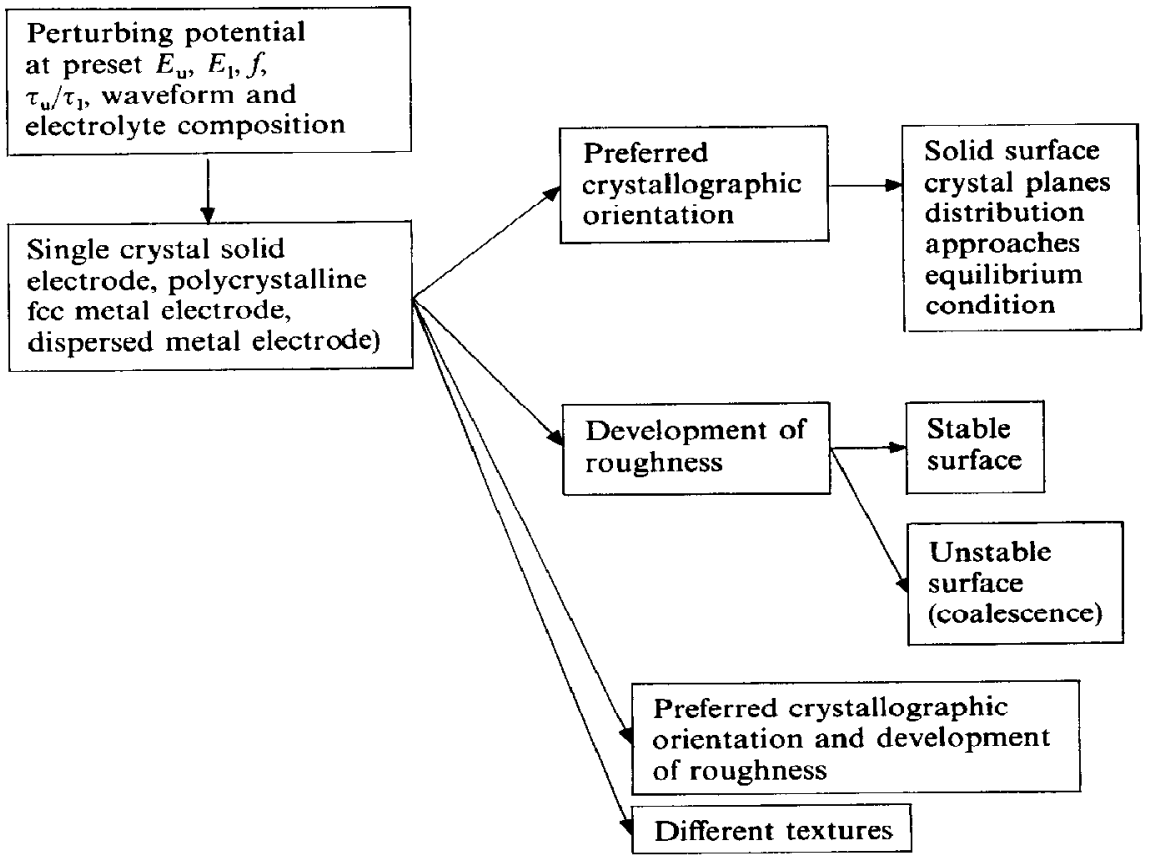

This new approach to obtain reproducible solid electrode surfaces ( $\mathrm{Pt}, \mathrm{Rh}, \mathrm{Au}, \mathrm{Pd}$, etc) can be improved through a more complete knowledge of the kinetics and mechanisms of the different processes involved, as well as of the structure of the phases at the atomic level. This will provide a new look for the solid electrode surface in terms of its preparation and structure, supplying for the first time direct information about the type and the density of surface sites, the domains of flat surfaces, and the kind and geometry of superclusters at the surface, which are essential to turn the solid electrode surface from a black box into a transparent one. The implications of these achievements are obvious both from the standpoint of rationalizing the elect rochemical work at solid electrodes as well as for possible practical applications because the above described procedures can be applicable also to dispersed metal electrodes[61]. These facts allow to forsee closer the possibility of a solid electrode surface engineering. integrated Approach. Studies in Surface Science and Catalysis, 13, Elsevier, Amsterdam (1983)

3. B. Lang, R. W. Loyner and G. A. Somorjai, Surf. Sci. 30, 440 (1972).

4. J. J. F. Scholten, Anal. Quim. A81, 475 (1985).

5. J. J. F. Scholten, Anal. Quim. A81, 485 (1985).

6. D. M. Kolb, J. Vac. Sci. Technol. A4, 1294 (1986).

7. K. Kinoshita, in Modern Aspects of Electrochemistry (Edited by J. O'M. Bockris B. E. Conway and R. E. White), Vol. 14, p. 557, Plenum Press. New York (1982).

8. A. Visintin, W. E. Triaca and A. J. Arvia, J. electroanal. Chem. 221, 239 (1987).

9. S. Trasatti and O. A. Petrii, IUPAC Commision on Electrochemistry (1.3), in preparation.

10. K. Kinoshita and P. Stonehart, in Modern Aspects of Electrochemistry (Edited by J. O'M. Bockris and B. F. Conway), Vol. 12, p. 183, Plenum Press, New York (1977).

11. N. García (editor), STM ' 86 , in Surf. Sci. 181, (1/2) (1987).

12. G. Binnig and H. Rohrer, IBM J. Res. Develop. 30, 355 (1986). 
13. J. Klein, S. Gauthier, S. Rousset and W. Sacks, $J$. Microsc. Spectrosc. Electron. 12, 403 (1987).

14. L. Vásquez, J. Gómez, A. M. Baró, N. García, M. L. Marcos, J. González-Velasco, J. M. Vara, A. J. Arvia, J. Presa, A. Garcia and M. Aguilar, J. Am. chem. Soc. 109, 1730 (1987).

15. J. Gómez, L. Vásquez, A. M. Baró, C. Alonso, E. González, J. González-Velasco and A. J. Arvia, J. electroanal. Chem. 240, 77 (1988).

16. A. C. Chialvo, W. E. Triaca and A. J. Arvia, J. electroanal. Chem. 146, 96 (1983).

17. A. C. Chialvo, W. E. Triaca and A. 3. Arvia, J. electroanal. Chem. 171, 303 (1984).

18. R. C. Salvarezza, C. Alonso, L. Vásquez, A. M. Baró and A. J. Arvia, Surf. Sci., submitted.

19. A. M. Castro Luna, M. C. Giordano and A. J. Arvia, $J$. electroanal. Chem., in press.

20. B. Beden, F. Hahn, S. Juanto, C. Lamy and J.-M. Léger, J. electroanal. Chem. 225, 215 (1987).

21. B. Beden, F. Hahn, S. Juanto, C. Lamy and J.-M. Léger, J. electroanal. Chem. 237, 119 (1987).

22. B. Beden, F. Hahn, S. Juanto, C. Lamy and J.-M. Léger, $J$. electroanal. Chem., in press.

23. J. C. Canullo, W. E. Triaca and A. J. Arvia, J. electroanal. Chem. 175, 337 (1984).

24. R. M. Cerviño, W. E. Triaca and A. J. Arvia, J. electroanal. Chem. 182, 51 (1985).

25. A. J. Arvia, J. C. Canullo, E. Custidiano, C. L. Perdriel and W. E. Triaca, Electrochim. Acta 31, 1359 (1986).

26. A. Visintin, J. C. Canullo, W. E. Triaca and A. J. Arvia, J. electroanal. Chem. 239, 67 (1988).

27. C. L. Perdriel, M. Ipohorski and A. J. Arvia, J. electroanal. Chem., 215, 317 (1986).

28. C. L. Perdriel, E. Custidiano and A. J. Arvia, J. electroanal. Chem. 246, 165 (1988).

29. J. C. Canullo, E. Custidiano, R. C. Salvarezza and A. J. Arvia, Electrochim. Acta 32, 1649 (1987).

30. A. Visintin, W. E. Triaca and A. J. Arvia, in preparation.

31. C. M. Ferro, A. J. Calandra and A. J. Arvia, J. electroanal. Chem. 59, 239 (1975).

32. B. E. Conway, H. Angerstein-Kozlowska, F. C. Ho, J. Klinger, B. MacDougall and S. Gottesfeld, Faraday Disc. chem. Soc. 56, 210 (1973).

33. L. Rebollo Neira, S. L. Marchiano and A. J. Arvia, Electrochim. Acta submitted.

34. C. Elsner, S. L. Marchiano and A. J. Arvia, in preparation.

35. E. B. Budevski, in A Comprehensive Treatise of Electrochemistry (Edited by B. E. Conwai, J.O'M. Bockris E. Yeager, S. U. M. Khan and R. E. White), Vol. 7, p. 399, Plenum Press, New York (1983).

36. A. R. Despic, in A Comprehensive Treatise of Electrochemistry (Edited by B. E. Conway, J.O'M. Bockris,
E. Yeager, S. U. M. Khan and R. E. White), Vol. 7, p. 451, Plenum Press, New York (1983).

37. R. Parsons, J. electroanal. Chem. 118, 1 (1981).

38. A. Hamelin, T. Vitanov, E. Sevastyanov and A. Popov, J. electroanal. Chem. 145, 225 (1983).

39. J. Bjerrum, G. Schwarzenbach and L. G. Sillén, Stability Constants of Metal Ion Complexes with Solubility Products of Inorganic Substances. Part 111: Inorganic Ligands, The Chemical Society, London (1958).

40. J. Gómez, L. Vásquez, A. M. Baró, N. Garcia, C. L. Perdriel, W. E. Triaca and A. J. Arvia, Nature 323, 612 (1986).

41. K. Itaya and S. Sugawara, Trans. Faraday Soc., in press.

42. E. V. Albano, H. O. Mártin and A. J. Arvia, Phys. Rev. B35, 9341 (1987).

43. E. V. Albano, H. O. Mártin and A. J. Arvia, Electrochim. Acta 33, 271 (1988).

44. E. Mola, J. L. Vicente, E. Custidiano and A. J. Arvia, Langmuir, in press.

45. A. E. Bolzán, A. M. Castro Luna, A. Visintin, R. C Salvarezza and A. J. Arvia, Electrochim. Acta, in press.

46. M. E. Vela, R. C. Salvarezza and A. J. Arvia, in preparation.

47. E. V. Albano, H. O. Mártin, R. C. Salvarezza, M. E. Vela and A. J. Arvia, J. electrochem. Soc., submitted

48. C. L. Perdriel, J. Zerbino and A. J. Arvia, in preparation

49. E. Bosco and S. K. Rangarajan, J.electroanal. Chem. 129, 25 (1981); J. chem. Soc. Faraday Trans. I, 77, 1673 (1981)

50. R. D. Armstrong, M. Fleischmann and H. R. Thirsk, J. electroanal. Chem., 11, 208 (1966).

51. R. O. Lezna, N. R. de Tacconi, L. Perdriel and A. J. Arvia, Spring Meeting, The Electrochemical Society, Philadephia (1987).

52. M. Marcos, J. M. Vara, J. González-Velasco and A. J. Arvia, J. electroanal. Chem. 224, 189 (1987).

53. B. Beden, F. Hahn, C. Lamy, J.-M. Léger, N. R. de Tacconi, R. O. Lezna and A. J. Arvia, in preparation.

54. A. M. Castro Luna, A. E. Bolzán, M. F. L. de Mele and A. J. Arvia, Z. phys. Chem., submitted.

55. S. Lichter and J. Chen, Phys. Rev. Lett. 56, 1396 (1986).

56. R. C. Salvarezza, C. Alonso, A. M. Baró and A. J. Arvia, in preparation.

57. R. C. Salvarezza, J. M. Vara and A. J. Arvia, in preparation.

58. T. Vicsek, Fractal in Physics (Edited by L. Pietronero and E. Tosatti), Elsevier, Amsterdam (1986); Phys. Rev. Lett. 53, 24 (1984).

59. A. R. Despic and K. I. Popov, J. appl. Electrochem. 1, 275 (1971).

60. J. Cl. Puippe and N. Ibl, J. appl. Electrochem. 10, 775 (1980).

61. A. Visintin, W. E. Triaca and A. J. Arvia, in preparation. 